\title{
RESPON BERBAGAI JENIS EKSTRAK BAGIAN TANAMAN (FEROMON) DALAM MENGENDALIKAN HAMA TANAMAN PADI (Oryza sativa L). SEBAGAI TEKNIK PENGENDALIAN HAMA TERPADU
}

\author{
Syafrizal Hasibuan, \\ Fakultas Pertanian Universitas Asahan \\ syafrizalhasibuan999@gmail.com
}

\section{RINGKASAN}

Respon berbagai jenis ekstrak bagian tanaman (Feromon) dalam mengendalikan hama tanaman Padi (Oryza sativa L) sebagai teknik pengendalian hama terpadu. Penelitian ini dilaksanakan di Desa Rawang Pasar IV Kecamatan Meranti, Kabupaten Asahan, dengan ketinggian tempat $\pm 15 \mathrm{~m}$ di atas permukaan laut. Penelitian ini dilaksanakan pada bulan Desember 2019-Maret 2020. Penelitian menggunakan Rancangan Acak Kelompok (RAK) Non Faktorial yang terdiri dari 6 taraf yaitu; $F_{0}=$ tanpa ekstrak (control), $F_{1}=$ Ekstrak Bunga Krisan, $F_{2}=$ Ekstrak Bunga Lavender, $F_{3}=$ Ekstrak Bunnga Mary gold liar, F4 = Ekstrak batang padi, dan $\mathrm{F}_{5}=$ Ekstrak tanaman padi muda. Hasil penelitian menunjukkan perlakuan terbaik adalah perangkap yang menggunakan feromon sebagai penolak pada perlakuan ekstrak bunga tembelek ayam (Mary gold) yang memiliki jumlah populasi tertangkap 110 imago serangga, sedangkan sebagai feromon penarik terdapat pada ekstrak bagian tanaman padi yang muda yaitu 625 imago serangga, kemudian diikuti perlakuan ekstrak bunga krisan, lavender dan batang tanaman padi. Jenis hama padi yang paling banyak tertangkap adalah ordo homoptera yaitu 814, diikuti dengan ordo hemptera yaitu 565, diptera 299 dan Lepidoptera sebanyak 89.

Kata Kunci ; Feromon, Ekstrak, Padi

\begin{abstract}
Abstrack
The study aimed to analyze the response of various types part of plant extracts (pheromones) to controlling rice plant pests (Oryza sativa L) using technique an integrated pest control. The research was carried out in the village of Rawang Pasar IV, Meranti District, Asahan Regency, with a height of $\pm 15 \mathrm{~m}$ above sea level. This research was conducted in December 2019-March 2020. The study using non-factorial randomized block design (RBD) consisting of 6 levels, namely; F0 = no extract (control), F1 = Chrysanthemum extract, F2 = Lavender flower extract, F3 = wild Mary gold Bunnga extract, F4 = rice stem extract, and F5 = young rice plant extract. The results showed that the best treatment was a trap that used pheromones as a repellent in the treatment of Mary gold flower extract which was a total population of 110 insects caught, while as a pulling pheromone found in the extracts of young rice plant parts, 625 insects, then followed. Chrysanthemum, lavender, and rice plant stem extract treatment. The type of rice pest that was caught most was the order Homoptera, namely 814 , followed by the Hemptera order, namely 565, Diptera 299, and Lepidoptera, which were 89.
\end{abstract}

Kata Kunci : Feromon, Ekstrak, Padi 


\section{PENDAHULUAN}

Komoditas padi sebagai sumber pangan utama yang merupakan tanaman yang banyak ditanam oleh petani di Indonesia. Pangan merupakan kebutuhan dasar/esensial bagi setiap manusia yang tidak dapat tergantikan dan ditunda pemenuhannya. Dalam upaya pemenuhan kebutuhan pangan, Serangan hama merupakan kendala utama dalam pembudidayaan tanaman padi. Pengendalian hama terpadu (PHT) merupakan konsep yang perlu diterapkan oleh petani padi yaitu dengan memadukan teknik pengendalian hama yang kompatibel.

Konsep PHT berkembang dan diterapkan dilandasi prinsip yaitu pemahaman ekosistem pertanian, biaya manfaat pengendalian hama, toleransi tanaman terhadap kerusakan, populasi hama yang dipertahankan agar musuh alami dapat berkembang dalam menjalankan fungsinya sebagai pengendali ekosistem pertanian, pemanfaatan dan pelestarian musuh alami, budidaya tanaman yang sehat, pemantauan ekosistem (hama, musuh alami, tanaman dan komponen ekosistem lainnya), pemberdayaan petani dan pemasyarakatan konsep PHT. Unsur dasar PHT adalah pengendalian alami, pengambilan sampel (pemantauan rutin), aras ekonomi pengendalian hama, dan pemahaman ekologi dan biologi hama (Untung, 2010)

Berdasarkan SK Menteri Pertanian No. 390/KPTS/TP.600/5/1994 tentang pedoman penyelenggaraan program nasional PHT, Pengendalian Hama Terpadu (PHT) merupakan upaya pengendalian populasi atau tingkat serangan organisme pengganggu tumbuhan dengan menggunakan satu atau lebih dari berbagai teknik

Adapun OPT dari tanaman padi dari golongan serangga tersebut adalah
1. Ordo Lepidoptera yaitu, PBP putih Scirpophaga innotata (Walker) ; PBP bergaris Chilo suppressalis (Walker) PBP Merah jambu Sesamia inferens (Walker) Lepidoptera: Noctuidae ; Ulat tanduk hijau (green horned caterpillar) Melanitis leda ismene Cramer Lepidoptera: Satyridae ; Ulat tentara/grayak (armyworm) Spodoptera mauritia acronyctoides (Guenée) Mythimna separata (Walker) Spodoptera exempta (Walker) Spodoptera litura (Fabricius) (jarang merusak padi) Noctuidae : putih palsu (leaffolder) Cnaphalocrocis medinalis (Guenée) Lepidoptera: Pyralidae ; Ulat jengkal-palsu hijau (green semilooper) Naranga aenescens (Moore) Lepidoptera: Noctuidae

2. Ordo Homoptera seperti Wereng coklat (brown planthopper $=\mathrm{BPH}$ ) Nilaparvata lugens (Stål) Delphacidae ; Wereng hijau (green leafhopper) Nephotettix virescens (Distant) Nephotettix nigropictus (Stål) Nephotettix cincticeps (Uhler) Nephotettix malayanus Ishihara \& Kawase Cicadellidae

3. Ordo Hemiptera adalah Kepinding tanah (black bug) Scotinophara coarctata (Fabricus) Hemiptera: Pentatomidae ; Walang sangit (rice bug) Leptocorisa oratorius (Fabricius) Hemiptera: Alydidae

4. Ordo Orthoptera Orong-orong (mole cricket) Gryllotalpa orientalis Burmeister: Gryllotalpida, Valanga nigricornis

5. Ordo Diptera Ganjur (gall midge) Orseolia oryzae (Wood-Mason) Diptera: Cecidomyiidae ; Lalat bibit (rice whorl maggot) Hydrellia philippina Ferino Diptera: Ephyridae

Feromon, berasal dari bahasa Yunani 'phero' yang artinya 'pembawa' dan 'mone' 'sensasi'. Feromon merupakan sejenis zat kimia yang berfungsi untuk merangsang dan memiliki daya pikat seks 
pada hewan jantan maupun betina (Anomin, 2013). Zat ini berasal dari kelenjar eksokrin yang digunakan oleh makhluk hidup untuk mengenali sesama jenis, individu lain, kelompok, dan untuk membantu proses reprodukikarena pheromones adalah senyawa alami tubuh. Berbeda dengan hormon, feromon menyebar ke luar tubuh dan hanya dapat mempengaruhi dan dikenali oleh individu lain yang sejenis (satu spesies).

Ketika pertama kali ditemukan pada serangga, feromon banyak dikaitkan dengan fungsi reproduksi serangga. Penemu zat feromon pertama kalinya pada hewan (serangga) adalah Jean-Henri Fabre, ketika pada satu musim semi tahun 1870 an pengamatannya pada ngengat 'Great peacock' betina keluar dari kepompongnya dan diletakkan di kandang kawat di meja studinya untuk beberapa lama menemukan bahwa pada pada malam harinya lusinan ngengat jantan berkumpul merubung kandang kawat di meja studinya.

Fabre menghabiskan tahun-tahun berikutnya mempelajari bagaimana ngengat-ngengat jantan 'menemukan' betina-betinanya. Fabre sampai pada kesimpulan jika ngengat betina menghasilkan 'zat kimia' tertentu yang baunya menarik ngengat-ngengat jantan Komunikasi melalui feromon sangat meluas dalam keluarga serangga. Feromon bertindak sebagai alat pemikat seksual antara betina dan jantan. Jenis feromon yang sering dianalisis adalah yang digunakan ngengat sebagai zat untuk melakukan perkawinan (Anonim, 2013).

Setiap organisme memiliki jenis feromon yang berbeda seperti halnya pada serangga baik sebagai hama pada tanaman tertentu maupun yang berperan pada tanaman tertentu, diantaranya seperti feromon sex, feromon agregasi, feromon jejak, feromon penunjuk jalan. Dalam hal ini akan dijelaskan lebih lanjut mengenai feromon dan feromon sex pada beberapa serangga antara lain Anonim (2013) .
Alomon adalah zat yang digunakan untuk komunikasi antargenus. Namun, feromon adalah isyarat kimiawi yang terutama digunakan dalam genus yang sama dan saat disekresikan oleh seekor semut dapat dicium oleh yang lain. Saat semut menyekresi cairan ini sebagai isyarat, yang lain menangkap pesan lewat bau ataurasa dan menanggapinya. Penelitian mengenai feromon semut telah menyingkapkan bahwa semua isyarat disekresikan menurut kebutuhan koloni. Selain itu, konsentrasi feromon yang disekresikan semut bervariasi menurut kedaruratan situasi (Anonim,2013).

Feromon dan alomon merupakan bahan kimia yang disekresi keluar tubuh serangga oleh kelenjar eksokrin sehingga bereaksi di luar tubuh (antar individu). Feromon menjembatani komunikasi individu dalam satu spesies. Kegunaannya beragam mulai dari daya tarik antar kelamin, mencari pasangan, mengisyaratkan bahaya, menandai jejak dan wilayah, serta berbagai interaksi intraspesifik lainnya. Sedangkan allomon merupakan bahan kimia yang bekerja menjembatani komunikasi antar spesies dengan keuntungan bagi penghasil allomonnya. Allomon dipergunakan untuk mengusir predator, membingungkan mangsa, dan memediasi interaksi simbiotik (Winoto, 2010).

Menurut Sutrino (2010) komunikasi kimiawi terjadi apabila Senyawa penghubung pada tumbuhan dan serangga fitofagus komunikasi serangga dengan lingkungan melalui perantaraan senyawa kimia yg disebut Semiokhemikal. Semiokhemikal digolongkan menjadi 2 bagian yaitu antara sebagai berikut:

\section{Feromon}

2. Alelokhemik terbagi menjadi beberapa senyawa antara lain:

Allomone, senyawa ini menimbulkan respon penolakan

> Kairomone, senyawa ini menimbulkan respon menarik kehadiran serangga 
Synomone, senyawa ini menimbulkan respon simbiotik

Apneumone, senyawa penghubung antara serangga dengan benda mati

Alomon adalah zat yang digunakan untuk komunikasi antargenus. Feromon adalah isyarat kimiawi yang terutama digunakan dalam genus yang sama. Nurnasari (2015) melaporkan, berdasarkan fungsinya ada dua kelompok feromon yaitu:

a. Feromon "releaser", yang memberikanpengaruh langsung terhadap sistem syaraf pusat individu penerima untuk menghasilkan respon tingkah laku dengan segera. Feromon ini terdiri atas tiga jenis, yaitu feromon seks, feromon jejak, dan feromon alarm.

b. Feromon primer, yang berpengaruh terhadap system syaraf endokrin dan reproduksi individu penerima sehingga menyebabkan perubahan-perubahan fisiologis.

Lebih lanjut Sutrisno (2010), menjelaskan bahwa feromon dapat dibedakan menjadi beberapa jenis, diantaranya :

i. Feromon seks;

ii. Feromon jejak;

iii. Feromon alarm;

iv. Feromon agregasi;

v. Feromon penanda wilayah dan penunjuk jalan.

Feromon agregasi adalah feromon yang diperlukan untuk mengumpulkan anggota koloni atau pun individu dan mempengaruhi perilakunya sebagai suatu individu. Kegunaan feromon ini berkisar dari penunjang perilaku makan, mating, berlindung, oviposisi, sampai ke perilaku yang belum terdeteksi secara jelas. Ada yang berkorelasi dengan musim (hibernasi), amplitudo harian (agregasi istirahat), berkaitan dengan stadia pertumbuhan (larva yang bersifat gregarius) dan perilaku mengumpul lainnya. Setelah sumberdaya yang sementara atau terbatas habis, maka agregasi akan terhenti dengan sendirinya (Winoto, 2010).

Feromon agregasi tersebar penggunaannya pada berbagai ordo seperti misalnya Orthoptera, Homoptera, Hemiptera, Coleoptera dan Hymenoptera. Familia yang paling banyak dipelajari adalah Scolytidae, Coleoptera; terutama pada kumbang kulit kayu; seperti genus Dendrocnotus dan Ips. Yang menarik, hampir semua feromon agregasi kumbang kulit kayu adalah monoterpen yang secara rumus bangun mirip dengan jenis yang dihasilkan oleh pohon inangnya. Reaksi agregasi merupakan tanggapan terhadap campuran molekul serupa yang saling menunjang efektivitas masing-masing. Komponen molekul serupa semacam itu membentuk suatu kerja kimia yang disebut sinergistik. Masing-masing senyawa sinergis mungkin cukup efektif sebagai molekul tunggal, tetapi lebih efektif jika bahan tersebut bercampur, jauh lebih efektif dibanding sekadar jumlah total efektivitas masing-masing (Winoto, 2010).

Feromon Alarm merupakan feromon yang dipergunakan untuk memperingatkan serangga terhadap bahaya yang datang, apakah itu predator atau bahaya lainnya. Tanggapannya dapat berupa membubarkan diri atau membentuk pertahanan koloni. Beberapa anggota familia Hemiptera dan serangga sosial menggunakan feromon ini untuk menghadapi bahaya. Bahan feromon ini pada afid misalnya, dikeluarkan melalui kornikulanya, yang mengandung bahan feromon alarm umumnya farnesen, dan menyebabkan afid yang berada di sekitarnya menjatuhkan diri, menjauh atau meloncat pergi (Winoto, 2010).

Feromon jejak merupakan feromon yang digunakan untuk menunjukan arah kelompok/koloni suatu serangga. Contohnya pada semut,pada semut ini digunakan feromon sebagai penunjuk jejak 
(Winoto, 2010). Feromon penanda wilayah dan penunjuk jalan; Feromon seks. Menurut Sutrisno (2010) feromon memiliki beberapa fungsi yang sangat membantu dalam pengendalian hama serangga antara lain sebagai berikut

1. Mempertemukan jantan dan betina kawin

2. Agregasi pada makanan

3. Oviposisi

4. Alarm bila diserang

5. Kontrol perilaku kasta dalam semut

6. Stimulasi migrasi

7. Menghindari multioposisi

Mekanisme cara kerja feromon menurut Winoto (2010) Feromon dikeluarkan melalui abdomen pada segmen ke 4 dan 5 pada serangga yang disekresikan oleh kelenjar eksokrin. Struktur senyawa feromon yaitu alkohol dan aldehid. Struktur senyawa yang dihasilkan bersifat spesifik sehingga reseptor yang dipunyai spesifik pula. Setelah sampai di antena serangga target, senyawa feromon tersebut akan dicapai ke otak melalui sel saraf dan barulah diterima oleh sel penerima.

Kebanyakan molekul feromon berasal dari senyawa biokhemis biasa seperti asam lemak atau asam amino. Isyarat feromon menempati ruang tertentu dan tinggal sampai beberapa saat lamanya. Apabila suatu feromon menguap keluar dari sumbernya, maka konsentrasinya akan semakin meningkat seiring dengan semakin bertambahnya waktu. Seandainya tidak ada faktor lain seperti angin dan sebagainya, maka konsentrasi ini akan membentuk suatu ruang berisi konsentrasi feromon, dengan konsentrasi tertinggi pada sumber emisi dan makin menurun ke segala arah.

Agar dapat menimbulkan rangsang, harus ada serangga lain yang menangkap isyarat ini. Kebanyakan tanggapan atas rangsang ini seragam, yakni apabila konsentrasi feromon telah melebihi kadar konsentrasi tertentu. Semakin dekat konsentrasi semakin tinggi, demikian pula semakin menjauh dari sumber emisi konsentrasi semakin rendah dan tidak mampu menimbulkan rangsang. Dengan demikian terbentuk semacam ruang tempat serangga lain menangkap isyarat atau rangsang kimiawi untuk kemudian bereaksi menanggapi rangsang tersebut. Ruang semacam ini oleh Wilson dan Bossert disebut sebagai "ruang aktif" atau "active space" (Winoto, 2010).

Jika feromon dilepas dalam jangka waktu yang cukup lama, maka ruang aktif akan menjadi cukup besar. Ruang aktif yang lebih besar diperlukan bila penerima memiliki alat deteksi isyarat yang tak terlampau peka dibanding bila penerima memiliki alat yang peka. Dengan mengubah-ubah laju emisi, kepekaan penerima dan jenis isyarat yang dikeluarkan, maka serangga dapat mencapai tujuan komunikasi kimiawi berhubungan dengan perilaku tertentu.

Ada feromon yang mampu menarik serangga jenis kelamin lain pada jarak yang cukup jauh, ada pula yang bekerja pada jarak dekat dan penerima menanggapinya dengan serangkaian perilaku "courtship" atau mencari pasangan. Feromon seperti ini tidak diproduksi terus menerus, tetapi hanya ketika serangga telah mencapai usia cukup dewasa untuk kawin, dan bahkan itu pun pada saat tertentu saja. Telah cukup banyak jenis feromon seks yang dipelajari para peneliti, terutama karena mengubah perilaku kawin merupakan strategi yang cukup dapat diandalkan dalam rangka pengelolaan hama. Penelitian seperti ini pada mulanya berangkat dari usaha menemukan dan menjelaskan molekul feromonnya secara deskriptif, dan ketika jenis dan jumlah molekul yang diperoleh semakin banyak, penelitiannya bergeser ke arah analisis rinci dan kejelasan mekanisme kerja feromon (Winoto, 2010). 
Pada mulanya diduga bahwa masingmasing spesies memiliki kekhasan molekul feromon seks yang dipergunakan untuk memikat lawan jenisnya. Molekul ini diduga khas, unik dan menimbulkan rangsang bagi lawan jenis dalam spesies yang sama, tidak pada serangga lain. Pada kenyataannya yang terdapat di alam ternyata jauh lebih menarik dan lebih kompleks dari dugaan tersebut. Kebanyakan feromon merupakan campuran kompleks dari beberapa senyawa penimbul bau, dan campuran aroma demikian memiliki perbedaan arti yang dapat cukup luas hanya karena sedikit perbedaan kadar campurannya. Karena jenisnya yang menjadi beratus-ratus (atau bahkan beribu-ribu) oleh bentukan campuran senyawanya, maka di sini hanya akan diketengahkan contoh feromon seks pada ulat sutera dan kupu-kupu ratu saja (Winoto, 2010).

- Adapun tujuan dari penelitian ini adalah untuk mengetahui Adanya pengaruh perlakuan pemberian satu jenis feromon terhadap pengendalian hama terpadu terhadap hama tanaman Padi (Oryza sativa L.)

\section{METODE PENELITIAN}

\section{A. Tempat dan Waktu Penelitian}

Penelitian ini dilakukan di Pasar IV, Desa Rawang, Kecamatan Rawang Panca Arga, Kabupaten Asahan, Provinsi Sumatera Utara. Waktu penelitian pada bulan April sampai bulan Juli 2020.

B. Bahan dan Alat

Bahan yang digunakan antara lain areal tanaman Padi, Bunga Lavender, Bunga Krisan, Bunga Kotoran ayam, Cat warna hijau, tinner, lem serangga, spidol dan bahan lain yang mendukung.

Alat yang digunakan antara lain Plastik, mikroskop, botol aqua, tali rafia, patok sampel, alat tulis, , kalkulator, pisau, gunting dan peralatan lain yang dianggap perlu.

C. Metode Penelitian

Penelitian ini menggunakan Rancangan Acak Kelompok (RAK) Non Faktorial yaitu : $\mathrm{F}_{1}=$ Ekstrak Bunga Lavender $\mathrm{F}_{2}=$ Ekstrak Bunga Krisan $; \mathrm{F}_{3}=$ Ekstrak Bunga Kotora ayam $; \mathrm{F}_{4}=$ Ekstrak batang tanaman $\mathrm{F}_{5}$ $=$ Ekstrak Tanaman Padi Muda (pucuk)

D. Peubah Amatan

\section{Identifikasi Jenis Hama yang} Tertangkap

Serangga Hama terperangkap di identifikasi sampai tingkat spesies menggunakan kunci identifikasi serangga yang dibantu dengan lup atau mikroskop. Hama tersebut yang diamati dan dihitung setiap empat hari.

2. Populasi Imago Hama Tanaman padi yang Terperangkap

Pengamatan jumlah dan jenis hama apa saja yang tertangkap pada penelitian tersebut dimulai dari empat hari setelah pemasangan perangkap sampai penelitian selesai

\section{HASIL DAN PEMBAHASAN}

\section{Hasil Penelitian}

1. Identifikasi Hama Padi yang terperangkap

Hasil pengamatan 1-14 hari setelah pemasangan perangkap, kemudian dilakukan identifikasi secara morfologi hanya dijumpai 5 ordo serangga yang merupakan hama penting dari tanaman padi. Hal ini dapat dilihat pada Table 1. 
Tabel 1. Jenis Ordo yang tertangkap yang sebagai hama tanaman padi

No Ordo dan Species

1 Leptocorisa acuta Alydidae ; Hemiptera

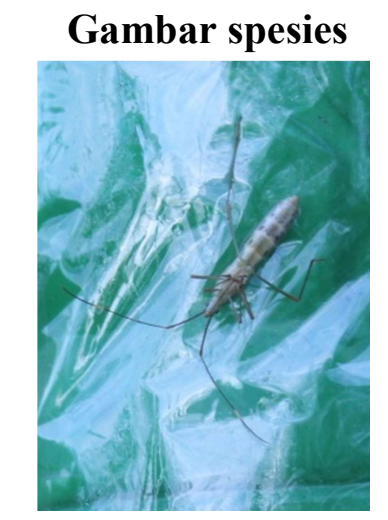

2 Nephotettix virescens ; Cicadelidae; Homoptera

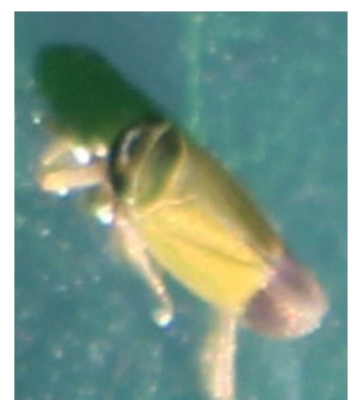

Recilia dorsalis ;

Cicadelidae;Homoptera

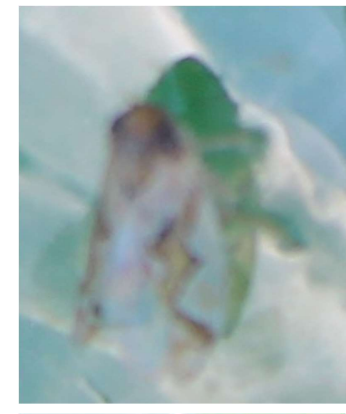

Sogatella furcifera

Cicadelidae;Homoptera

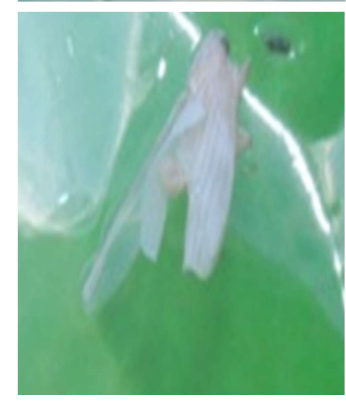

3 Musca domestica Muscidae ; Diptera

\author{
No Ordo dan Species \\ 4 Erionota thrax \\ Hesperiidae;Lepidoptera
}

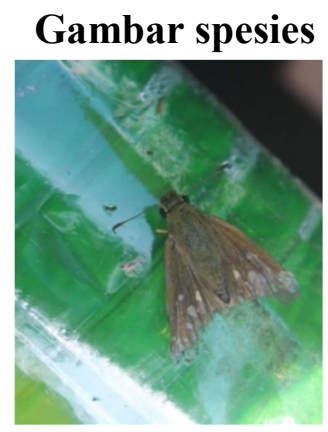

Dari hasil identifikasi hama yang paling merugikan tanaman padi terdapat 4 ordo dari mulai tanam sampai panen.

\section{Populasi Imago Hama Tanaman padi yang Terperangkap}

Hasil pengamatan dan analisis sidik ragam dapat dilihat bahwa pengaruh Feromon yang menggunakan berbagai perangkap warna menunjukkan adanya pengaruh yang berbeda nyata dengan menggunakan flourence dan warna terhadap hama yang terperangkap, sedangkan interaksi antara flourence dan warna memperlihatkan hasil yang tidak berbeda nyata. Untuk lebih detil hal ini dapat dilihat pada Tabel 2.

Tabel 2. Hasil Uji Beda Rataan perangkap Feromon Terhadap Populasi Imago Hama Tanaman padi Yang Tertangkap 20 HSPP

\begin{tabular}{|c|c|c|c|c|}
\hline Feromon & I & II & III & Rata -rata \\
\hline F0 & 13 & 10 & 14 & $12,33 \mathrm{a}$ \\
\hline $\mathrm{F} 1$ & 26 & 27 & 20 & $27,67 \mathrm{~b}$ \\
\hline $\mathrm{F} 2$ & 12 & 23 & 26 & $20,33 \mathrm{ab}$ \\
\hline $\mathrm{F} 3$ & 6 & 7 & 9 & $7,33 \mathrm{a}$ \\
\hline $\mathrm{F} 4$ & 10 & 8 & 7 & $8,33 \mathrm{a}$ \\
\hline F5 & 30 & 47 & 48 & $41,67 \mathrm{c}$ \\
\hline \multicolumn{5}{|c|}{$\begin{array}{l}\text { Keterangan : Angka-angka yang diikuti huruf } \\
\text { yang sama pada baris atau kolom yang sama } \\
\text { menunjukkan berbeda tidak nyata pada taraf } 5 \% \\
\text { dengan menggunakan DMRT }\end{array}$} \\
\hline
\end{tabular}

Berdasarkan data yang disajikan pada Tabel 2. dapat dilihat bahwa perangkap yang menggunakan Feromon sangat efektif dalam menolak serangga terlihat pada 
perlakuan F3 ekstrak bunga Marry gold rata-rata sebesar 7,33 yang tertangkap berbeda nyata dengan F5 ekstrak tanaman muda padi yang bersifat menarik serangga rata-rata sebesar 41, 67. Hal ini dapat dilihat pada grafik histrogram yang terdapat pada Gambar 1.

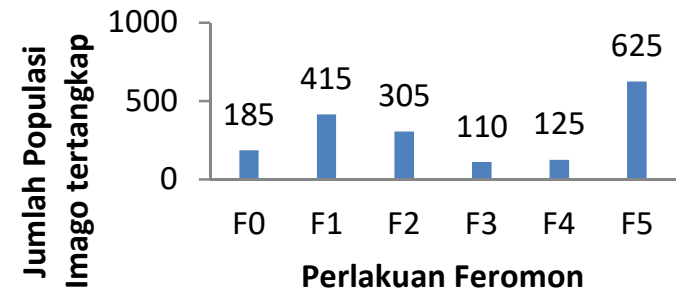

Gambar 1. Grafik histrogram jumlah Populasi Imago Hama pada Tanaman Padi Yang Tertangkap dengan menggunakan perangkap Feromon.

Dari gambar grafik histrogram pada Gambar 1. menunjukkan bahwa perlakuan $\left(\mathrm{F}_{0}\right)$ memiliki jumlah sebanyak 185 yang tidak berbeda nyata dengan $\mathrm{F}_{3}$ yaitu 110 dan $F_{4}$ yaitu sebesar 125 . Pada $\left(F_{1}\right)$ yaitu 415, namun berbeda tidak nyata dengan $\left(F_{2}\right)$ yaitu 305 , dan $F_{5}$ yaitu 625 berbeda nyata dari semua perlakuan.

Dari perangkap Feromon dan Berbagai Perangkap Feromon pada tanaman padi diperoleh ordo yang paling banyak tertangkap yaitu ordo Homoptera sebesar 814 dan Hemiptera sebesar 565. Diikuti ordo Diptera dan lepidoptera. Hal ini dapat dilihat pada grafik batang pada Gambar 2 .

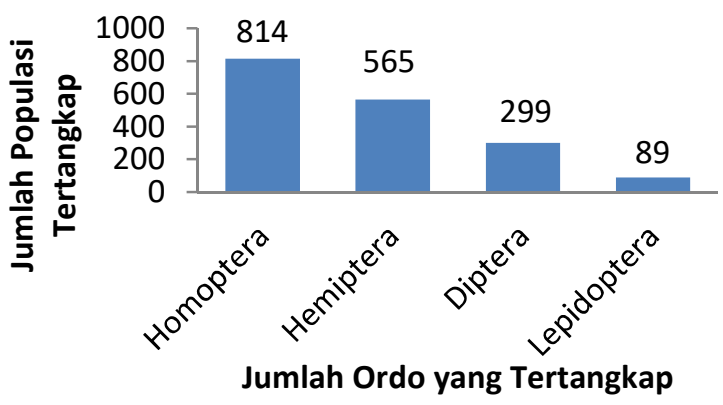

Gambar 2. Grafik diagram batang perangkap Feromon Terhadap Populasi Imago Hama pada Tanaman Padi Yang Tertangkap.

\section{Pembahasan}

Berdasarkan hasil penelitian diperoleh untuk jenis imago serangga yang tertangkap adalah secara berurutan dari mulai tertinggi sampai terendah yaitu ordo homoptera, hemiptera, dipteral dan Lepidoptera hal ini membuktikan bahwa ordo homoptera dengan jenis hama wereng sangat senang dari aroma bagian tanaman muda. Sedangkan untuk ordo hemiptera jenis walang sangit dan ordo diptera yaitu lalat sangat menyukai aroma yang spesifik yaitu aroma yang sangat menyengat dalam hal pencarian makanan. Untuk ordo Lepidoptera sangat menyukai aroma ekstrak bunga. Hal ini sesuai dengan literatur Natawigena, 1993 yaitu sesuai dengan tipe mulut dari pada serangga seperti yaitu menusuk menghisap, menjilat menghisap.

Dari hasil penelitian diperoleh ekstrak feromon yang dilakukan merupakan feromon yang bersifat menolak, hal ini dibuktikan dengan jumlah imogo serangga yang tertangkap tidak menyukai aroma tersebut sehingga imago yang tertangkap sangat sedikit. Menurut (Winoto, 2010) berbagai macam jenis ekstrak tanaman yang dilakukan dapat digunakan sebagai feromon penolak serangga, hal ini membuktikan bahwa feromon tersebut dapat mengendalikan serangga hama sehingga tanaman dapat terlindungi dari serangan hama tanaman padi tersebut.

Dari hasil penelitian diperoleh hasil bahwa sifat feromon tersebut sangat nyata sebagai aroma penolak dijumpai pada aplikasi ekstrak bunga Marry gold yang terlihat sedikit sekali dihinggapi serangga. Jenit tanaman ini tersmasuk tanaman refugia dan aroma penarik yaitu pada bagian tanaman yang muda sebab bagian tanaman yang muda memiliki aroma auksin yang disukai oleh serangga sebagai zat makanan. 


\section{KESIMPULAN DAN SARAN}

\section{A. Kesimpulan}

1. Perlakuan menggunakan ekstrak tanaman umumnya feromon yang bersifat menolak terutama ekstrak bunga kotoran ayam

2. Untuk perlakuan F4 bahwa sangat efektif sebagai feromon penolak (replant) dan F5 sebagai feromon penarik (atraktan).

3. Ordo yang paling banyak tertangkap dari perlakuan ini adalah ordo homoptera jenis wereng pada perlakuan F5 dan paling sedikit ordo Lepidoptera pada perlakuan F3

\section{DAFTAR PUSTAKA}

Anonim. 2013. Feromon.

http://id.wikipedia.org/wiki

/feromon. 5 Juni 2013.

Atkins, M. D. 1980. Introduction to Insect Behaviour. Macmillan Publishing Co. London. 273 pp

Baehaki. 2015. Strategi Pengelolaan

Serangga Hama di Lahan Pertanian untuk Menunjang Tercapainya Ketahanan Pangan di Indonesia. Dalam Seminar Nasional dan Musyawarah Anggota Perhimpunan Entomologi Indonesia (PEI) Cabang Bandung, Bandung, 15 Oktober 2015

Dora Carmona 2018. "Insect aggregation pheromones". www.msu.edu. Retrieved

Elzinga, R.J. 1978. Fundamentals of Entomology. Prentice Hall Inc. New Jersey : 325 hal.

Jelfina C. Alouw 2018 Feromon dan Pemanfaatannya Dalam Pengendalian Hama Kumbang
Kelapa Oryctes rhinoceros

(Coleoptera: Scarabaeidae)

Gedogan., 2016, Mengenal Lebih Dekat

Tentang Feromon Dan Manfaatnya, Wordpress.Com

Gomez, K.A., dan Gomez A.A. 2007. Prosedur Statistik untuk Penelitian Pertanian. UI-Press. Jakarta.

Kalshoven. L.G.E, 2001. Pest of Crops in Indonesia, Revised and Translated by Van swr Laan. PT Icthiar Baru Van

Hoeve. Jakarta Hlm 88-79

Natawigena, H. 1993. Dasar-dasar

Perlindungan

Tanaman. Penerbit Trigenda Karya.

Bandung.

Nurnasari, E. 2015. Pemanfaatan Senyawa

Kimia Alami Sebagai Alternatif

Pengendalian Hama Tanaman .

http://www.chem-is-try.org /artikel_kimia/kimia_pangan/ peman faatan-senyawa-kimia-alamisebagai- alternatif-pengendalianhama-tanaman/. 11 Juni 2015

Rukmana, R. dan Sugandi, U. 2010. Hama Tanaman dan Teknik Pengendalian. Kanisius.Yogyakarta

Iqbal , 2018 Pengujian Feromon Seks Pada

Kupu- Kupu Papilio memnon Linn. (Lepidoptera : Papilionidae) Di Laboratorium Universitas Pendidikan Indonesia. Jakarta

Sutrisno, S. 2010. Chemical Control Systems:Pheromones, Attractants , Repellents pada Hama Pemukiman http://www.pestclub.com/index. php?show $=$ news\&task $=$ show\&id $=12.5$ Juni 2009. 
Sunjaya, P.I. 1970. Dasar-Dasar Ekologi Serangga. Bagian Ilmu Hama Tanaman IPB Bogor. Hal : 63-91

Suyamto, 2010, Masalah Lapangan Hama, Penyakit Hara Pada Padi, Pusat Penelitan Dan Pengembngan

Tanaman Pangan, Jakarta

Untung, K. 2010. Pengantar Pengelolaan Hama Terpadu. Edisi kedua. Gajah Mada University Press

Winoto. 2010. Feromon, Allomon,

Kairomon: Sistem Komunikasi

Serangga, Konsep Dasar, Elektroantenogram (Eag), Olfaktometer Dan Uji Biologis Lainnya.11 Juni 2009.

Windra Priawandiputra dan Agus Dana Permana, 2015 Efektifitas Empat Perangkap Serangga dengan Tiga Jenis Atraktan di Perkebunan Pala (Myristica fragrans Houtt). Jurnal Sumberdaya Hayati November 2015 Vol. 1 No. 2, hlm 54-59 